\title{
A critical analysis of information society conceptualizations from an STS point of view
}

\author{
Eduard Aibar
}

Internet Interdisciplinary Institute (IN3), Universitat Oberta de Catalunya (UOC), eaibar@uoc.edu

\begin{abstract}
Science and Technology Studies (STS) have developed over the last four decades a very rich and deep analysis of the interaction between science, technology and society. This paper uses some STS theoretical and methodological insights and findings to identify persistent misconceptions in the specific literature on ICTs and society. Technological deterministic views, the taken-for-granted image of technological designs, the prospective character of many studies that focus mainly on potential effects, a simplistic view of uses and users, and an uncritical distinction between the technical and the social, are discussed as some of the most notable theoretical flaws in the field.
\end{abstract}

Keywords: Science and technology studies, ICT and society, theoretical models, technological determinism, users, information society

The concept of Information Society and the interaction between Information and Communication Technologies (ICT) and society in general have been the subject of many theoretical insights and a lot of studies in the last decades ${ }^{1}$. My purpose in this paper $^{2}$ is to discuss how some of these current approaches tend to reproduce old and very well known views of the relationship between technology and society, that is, between technological innovation and social change. Some of these views, I will argue, are based on assumptions that are not necessarily consistent with what we already knew about technology and society and the many ways they interact.

Since Science and Technology Studies (STS) have been critically analysing the interaction between science, technology and society for the last four decades and have developed a deep and very rich picture of its intricacies ${ }^{3}$, I would like to use their approach in order to identify some persistent misconceptions and, thus, show some opportunities for improving the present state of the art in the study of ICT and society.

I have not conducted a systematic survey of the literature for this paper. What follows is mostly a very informal view based on my own reactions and critical judgements on the literature I have come across in the last years. I mean both literature about the Internet and Society with a fairly general scope, and the more specific literature on eGovernment, i.e., the interaction of ICT with governments and politics, which I am most familiar with, because of my recent research.

\footnotetext{
${ }^{1}$ For a discussion of some of these approaches see Webster (2002).

${ }^{2}$ An earlier and shorter version of this paper was presented in the panel on Approaches towards ICT and Society Theories and Methodologies at the IADIS International Conference on ICT, Society and Human Beings that was held on the Algarve, Portugal, 21- 23 June 2009. I would like to thank Ana Waksberg-Guerrini for ideas and comments on an earlier draft of this paper.

${ }^{3}$ For a recent compilation of works in this interdisciplinary area of research, see Hackett et al. (2008).
} 


\section{Technological determinism}

My first claim is rather obvious. In many studies, Technological Determinism is still the dominant view and the main framework for analysing the relationship between ICT and society. It is also remarkable that Technological Determinism is widely present both in positive assessments and in negative views of the Information Society. On the one hand, impact talk - the most common symptom of technological deterministic approaches - is in fact pervasive in most papers. As a consequence, particular technologies are usually taken as something given or coming out of the blue: they are just there and social scientists are expected to explain what their effects on society will be.

ICT evolution is quite often implicitly assumed to follow an autonomous path of necessary and mechanistically joined steps, so further research into the shaping forces or actors is not considered necessary or very relevant. The social actors or social aspects involved are instead considered sometimes only as obstacles to the autonomous and unidirectional path of technological innovation, which seems to be powered by an internal momentum. Therefore, some authors talk about the cultural or social "barriers" to eGovernment, for instance, and others resort very easily to different kinds of "social" or "human" resistances to technological innovations along that path ${ }^{4}$.

Of course, the STS perspective does not imply that any impact-talk should be avoided per se. It is clear that technology has effects on, and sometimes deep implications for, many aspects of social life. But the very notion of 'impact' needs more critical attention, mainly because it implies a dubious separation of technology and the context that it is supposed to affect. It is interesting to note that Manuel Castells (1998), who has built the most articulated theorization of the information society, took great care in avoiding technological deterministic views of the role of ICT in the socalled informational society.

Another problem with impact talk is that it often results in key questions being couched in overly simplistic and ideological dichotomies that make an understanding of the new patterns of social interaction difficult (Woolgar, 2002, 7). When considering the possible effects of the Internet on politics, for instance, many authors build their research hypotheses linking Internet use to the reinforcing of democracy or to the exacerbation of its problems - crisis of legitimacy and decreasing rates of public participation in formal political processes. Other and more subtle phenomena receive less attention.

The main problem with the impact frame is that it usually induces effects or consequences of technological innovation to be treated as universal, predictable and unidirectional. In most cases, this is inaccurate. A large proportion of STS empirically based case studies have been, in fact, devoted to demonstrating that the uses and effects of technologies depend decisively on local social contexts.

ICTs alleged effects thus cannot be seen as independent of the social environment where they have actually been designed and created. We need more informed studies not only on technology effects on society, but on the way technologies (ICT) themselves are actually designed, developed and tested and thus shaped along those processes. We need also to bear in mind that innovation is not only a scalar magnitude but a vector - that is, something that has got another property worth of mention: direction.

\section{Revolutionary changes}

My second point is a sort of request for modesty. The way we academics tend to phrase our research questions in this area is often too grandiloquent - it seems we have been infected by the same virus that affects enthusiastic journalism, supply-side marketing, and oversimplified policy visions, maybe because academic social science is often in dialogue with them. Whenever we envisage changes (linked to ICT) it seems they have to be big, revolutionary and dramatic. And this

\footnotetext{
${ }^{4}$ For a critical discussion on the use of 'resistance to change' as an explanatory concept for eGovernment analyses, see Welp, Urgell and Aibar (2007).
} 
kind of research megalomania affects not only the deepness of those changes but their scope. Things need to change a lot and worldwide.

A first recommendation to avoid this kind of pitfall should be disaggregation. I think we need to disaggregate society, users and even technologies much more. Otherwise our conclusions lose relevance and soundness. Whenever we talk about important changes we have to specify how important they are, in what particular circumstances and for whom.

In that context, the performative character of technology narratives should also not be forgotten. Not only does technology have effects, but so also do discourses about them. In the field of eGovernment, for instance, the aggressive and deterministic views and stories produced by consulting, software and hardware companies have had a very deep influence in the way ICT and the Internet have been used in the last decade by many governments ${ }^{5}$.

\section{Foresight and speculation}

Another problematic feature of some literature - particularly evident in the field of eGovernment but also present to a great extent in other areas of ICT \& society research - is the focus on future changes or impacts. Although recent past or even present is still not very well understood in most areas of ICT use, there is often a surprising focus on potential situations or effects - much more than on present uses and implications.

The main problem with foresight and prospective studies or prophecies is that they show an intrinsic tendency to fail. There is indeed a long and much-documented tradition of unfulfilled prophecies about ICT and the Internet: from the global village and the end of the urbanization process, to the paperless office or the spread of telework. The deep imbalance between speculation and empirical research is still one of the more serious shortcomings of present social research about the information society.

\section{Users as producers}

In the last decade there has been an increasing amount of scholarship devoted to the understanding of user-technology relations - this has represented a remarkable shift from the older and more usual study of designers and producers of technology that, for many years, was the main focus of attention for most social analysis of technology (Oudshoorn and Pinch, 2003). This shift in orientation has also occurred in the social study of ICT - but not so much in eGovernment research where there is often no longitudinal engagement with projects or initiatives that are mostly analyzed on their design side, paying less or little attention to their actual use or lack of it (Heeks i Bailur, 2007). But although there are many studies of users and uses of ICT in very different areas, there are still some insights from this broader literature on users and technological artefacts that could be particularly useful. I will only mention a couple of them.

First of all, users should be understood as active and not passive participants in the evolution of technology. They are not simple consumers, but active agents in the domestication and adaptation of artefacts to their own objectives and interests. We should not forget that the very origin and evolution of the Internet shows this remarkable blurring of the distinction between users and producers (Abbate, 1999). Second, social scientists should place more emphasis on the disaggregation needed to understand the many possible uses of any technology. Another important lesson from STS in this area is that there is never a 'correct' use of a technology: there are only intended, recommended, expected or dominant uses. Use is never deduced from the technology itself and though designers or producers invest a lot of time and resources to discipline their future users, it is always possible that they end up with totally new and surprising uses.

A last point on this issue is that we should be careful not to be too quick to equate the involvement of users in many areas of ICT with a process of democratization - especially when we

\footnotetext{
${ }^{5}$ See Dunleavy et al. (2006) for the role of IT corporation in eGovernment.
} 
are dealing with company-owned technical systems that have been mainly designed as tools for profit making.

\section{The technical versus the social}

Also present in current analytical approaches to ICT and Society is the sharp distinction, often taken for granted, between technological issues, on the one hand, and social, political, or cultural issues on the other - another element of concern from an STS point of view. This distinction is also meant to imply - sometimes explicitly - that technology, or technical issues, are objective, solid, stable and not open to much interpretation, whereas the social is always subjective, weak and at the core of different, deep and long-lasting controversies.

This view often makes descriptions of technology itself, of what it is, of what people can do with it, as self-evident or uncritical depictions of a lifeless artefact. In general, we often grant technologies with much more stability than they deserve. We talk about the Internet and compare old uses (let us say eight year-old uses) and users with present ones, without paying much attention to the changes in applications that have occurred during that time. Just as we talk about present social networks without noticing the differences between them, and what is more important, without bearing in mind that these very differences are not accidental or by chance, but the outcome of many deliberate and sometimes 'small' decisions hidden inside their black boxes.

We also tend to forget that the very nature of the technology and society dynamics is constantly reshaping what is taken as technical or social (Latour, 2005). Sometime ago software was a technical issue; but today, when controversies over free and open-source software, or over the P2P networks that allow the exchange of files, have entered the agenda of many governments and parliaments, they are not purely technical issues anymore (Moglen, 2003).

On the other hand, pure social or cultural phenomena are also difficult to find. In the eGovernment literature many models assume a certain clash between technology and organization (public administrations, in this case), thus overlooking two important points.

Firstly, technologies never come alone. In the particular case of eGovernment, they come hand in hand with consultancy or ICT companies with very particular views and interests that actually shape the final designs of the information systems they sell. Secondly, organizations are always based and built around specific technical artefacts - from buildings to telephones - and cannot be fully understood without taking them into account (Orlikowsky, 2000).

In the eGovernment literature, Max Weber's description of bureaucracy is often used to describe or even define what kind of organization a bureaucracy is. The problem is that this resort to Weber's theory is often not complete. Most papers only mention the soft elements of a bureaucracy (the way civil servants are appointed, the way decisions are based on rules and law, etc.) but forget to talk about the information technical system (based on paper, files, archives) that lies at the core of any public administration - from the early Egyptian or Babylonian states to the present -, an aspect that Weber himself considered the nucleus of any bureaucracy. It is also forgotten, sometimes, that computers entered many public administrations in the early sixties - long before the term eGovernment had become popular.

As a result, the outcomes or effects of any eGovernment project or initiative cannot be explained by a simple conflict between technology and organization - what is at stake is a clash between different socio-technical frames or paradigms (Bijker, 1992).

\section{The online mirage}

Another element of concern is the implicit assumption some studies made about the relationship between the online and the offline. In fields like eGovernment where the main question is to determine to what extent ICT has changed a traditional institution and organization, there has been -_and still is -_a tendency to "decouple" electronic or virtual entities from 'real entities'.

On one side many empirical studies on eGovernment - most of them in fact - have focussed mainly on the online side. The favourite methodological tool has been web analysis and studying 
eGovernment has come to mean ${ }_{2}$ for many authors, counting e-services available at government portals or determine whether all administrative units show an email address where citizens may send a complaint or ask a question.

Of course those data are interesting and in many cases deserve a great deal of attention, but although web analysis is the easiest way to do empirical research - basically because you can do it at your own desk - it has some serious drawbacks.

If we want to analyse changes within an organization it is not wise to limit our empirical data to its website. Websites are part of an organization, and sometimes a very important part. However, they are not just mirrors of what happens in the rest of the organization. This is particularly true for governments, where websites - in terms of the usual eGovernment achievements (efficiency, efficacy, transparency, and responsiveness) - may give us a totally wrong idea of what is really going on in the backroom. They are best seen as distorted mirrors producing sometimes impressive mirages (Waksberg and Aibar, 2007).

In fact, from my point of view and my own experience in this field, the most interesting issues come from the analyses of what happens in the middle, that is, in the traffic between websites and information systems and the rest of the organization. It is always the transactions between online and offline elements that constitute the best area for analyses. And research about them cannot stop at the screen. It must go farther, deep inside the organization and also use the traditional empirical methods of social science research.

\section{Conclusions}

I have discussed a few theoretical problems that can easily be detected in many current approaches to ICT and society. Most of these problems have to do with a too simplistic perspective on the ways technological innovation and social change are usually intertwined, with technological determinism and the impact framework being the most common misconceptions. Since STS scholars have built in the last decades a very deep and rich understanding, through different analytical models, of the social dimensions of technology, it is useful to confront this understanding with specific theoretical approaches to a particular technology or set of technologies, including ICT.

In fact, this is not completely unprecedented since a few scholars, particularly those working in the field of social informatics, have repeatedly pointed out the need to analyse ICT as sociotechnical networks (Kling, 1999) very much in line with mainstream STS studies. But perhaps due to the fact that current studies on ICT and society show an increasing diversity of disciplinary origins, it seems that the insights and research principles of social informatics and STS still have limited influence in many areas.

Finally, I would also like to observe that a great amount of research on ICT and society lies beyond my criticism, although for the wrong reason. Atheoretical approaches with no use of theory at all are still quite common. This applies particularly to the field of eGovernment, where it is relatively easy to find papers with no analytical model being tested and no reference to or discussion of previous models or theories (Heeks and Bailur, 2007). Many studies or papers show in fact an almost complete absence of statements on research methods and have a purely descriptive character in which empirical data are collected and analysed with little scientific rigor.

\section{References}

Abbate, J. (1999). Inventing the Internet. Cambridge: MIT Press.

Bijker, W. (1992). The Social Construction of Fluorescent Lighting, or How an Artifact Was Invented in Its Diffusion Stage. In W.E. Bijker \& J. Law (Eds.), Shaping Technology / Building Society. Studies in Sociotechnical Change. (pp. 75-102). Cambridge: MIT Press.

Castells, M. (1998). The Information Age. Economy, Society and Culture. Oxford: Malden.

Dunleavy, P., Margetts H., Bastow S. \& Tinkler J. (2006). Digital Era Governance: IT Corporations, the State and eGovernment. Oxford: Oxford University Press.

Hackett, E.J., Amsterdamska O., Lynch M. \& Wajcman J. (2008). The Handbook of Science and Technology Studies. Cambridge: MIT Press. 
Heeks, R. \& Bailur, S. (2007). Analysing eGovernment Research. Government Information Quarterly, 22(2), 243-265. Latour, B. (2005). Reassembling the Social. An Introduction to Actor-Network-Theory. Oxford: Oxford University Press. Moglen, E. (2003). Freeing the Mind: Free Software and the Death of Proprietary Culture. Fourth AnnualTechnology and Law Conference. Keynote ardes. Portand (Maine), June 29.

Orlikowsky, W. (2000). Using Technology and Constituting Structures: A Practical Lens for Studying Technology in Organizations. Organization Science, 11(4), 404-428.

Oudshoorn, N. \& Pinch T. (2003). How Users Matter: The Co-Construction of Users and Technology. Cambridge: MIT Press.

Waksberg, A.\& Aibar E. (2007). Towards a Network Government? A Critical Analysis of Current Assessment Methods for EGovernment. Lecture Notes in Computer Science 4656, 330-341.

Webster, F. (2002). Theories of the Information Society. London: Routledge.

Welp, Y., Urgell F. \& Aibar, E. (2007). From Bureaucratic Administration to Network-Administration? An empirical study on e-Government focus on Catalonia. Public Organization Review, 7(4), 299-316.

Woolgar, S. (2002). Virtual Society? Technology, Cyberbole, Reality. Oxford: Oxford University Press.

\section{About the Author}

Eduard Aibar

Eduard Aibar is an Associate Professor at the Universitat Oberta de Catalunya. He is affiliated with the Department of Arts and Humanities and the research group on eGovernance at the Internet Interdisciplinary Institute. He has been the founding director of the PhD Programme on the Information and Knowledge Society and is currently the Vice President for Research. He has published a range of works and papers on the interaction between technological innovation and social change, using STS approaches and, most recently, on eGovernment, where he focuses mainly on the organizational shaping of IT projects. 